Article

\title{
"Self-Employed" in Caregivinghood: The Contribution of Swedish Informal Caregivers' Environmental and Contextual Resistance Resources and Deficits
}

\author{
Monica Eriksson *, Mia M. T. Wennerberg, Solveig M. Lundgren and Ella Danielson \\ University West, Department of Health Sciences, Center on Salutogenesis, 46186 Trollhättan, Sweden; \\ miamtolsson@hotmail.com (M.M.T.W); solveig.lundgren@fhs.gu.se (S.M.L); ella.danielson@fhs.gu.se (E.D.) \\ * Correspondence: monica.eriksson@hv.se; Tel.: +46-520-223-861
}

Received: 28 February 2017; Accepted: 14 July 2017; Published: 22 July 2017

\begin{abstract}
Informal caregivers provide the majority of care for older adults residing in their own homes. Caregivinghood, a new evidence-based concept, describes a time of life when relatives provide care at home. These caregivers need knowledge regarding resources to help them resolve the challenges they encounter. The theoretical framework underpinning this study is Antonovsky's salutogenic theory of health. This study had two aims: (1) to examine the salutogenic core concepts Generalized and Specific Resistance Resources and Deficits (GRRs/SRRs and GRDs/SRDs) described by Swedish informal caregivers as originating from the environmental and contextual domain of caregivinghood and (2) to discuss how this new knowledge might contribute to the development of health promotion initiatives. This qualitative and theory driven study used inductive and deductive data analysis. Data were gathered through salutogenically guided face-to-face interviews of 32 Swedish informal caregivers. In addition, the study relied on the salutogenic core concepts Specific and Generalized Resistance Resources and Deficits originating from their environment and context. Being in empowering surroundings reflects the presence of usable SRRs/GRRs, whereas Struggling in impeding surroundings reflects the presence of SRDs/GRDs. The results indicate that health-enhancing support has to be individualized (SRRs/SRDs) and generalized (GRRs/GRDs). This study's salutogenic approach and the methodology enhance the understanding of the mechanisms behind the development of Sense of Coherence. The results contribute both empirically and theoretically to strengthen health promotion research and practice when developing activities and support for caregivers in stressful situations, such as informal caregiving.
\end{abstract}

Keywords: caregivinghood; Generalized and Specific Resistance Resources; Generalized and Specific Resistance Deficits; home care; theory driven within-case and across-case analysis; salutogenesis; informal caregiver; caregiver support; qualitative

\section{Introduction}

Demographic trends indicate that the older population is increasing; that is, more and more people are getting older. This change is challenging for those people who provide services and care to older people. Informal caregivers provide the majority of care for older adults residing in their own homes [1]. According to EUROCARERS (https://www.eurocarers.org/) and EUROFAMCARERS (https://www.uke.de/extern/eurofamcare/), the emphasis on community care for the elderly makes caregivers a fast-growing population with specific needs related to their health. The population is heterogeneous, but they share something in common: the way they interact with their immediate context and environment. Depending on individual characteristics, this interaction may either enhance 
or worsen their health. This seems to be a health problem for caregivers that needs to be addressed when talking about promoting health and quality of life for older people. To meet these particular challenges, knowledge regarding the duality of caregiving, positive as well as negative outcomes, is essential. A paradigm shift emphasizing this duality is emerging within caregiving research, but progress towards a more balanced picture is slow [2]. Far less knowledge exists about the resources caregivers use to resolve challenges they encounter during caregiving, than knowledge about negative health outcomes associated with not being able to resolve them. This is unfortunate, since studies suggest that people and systems adopting the salutogenic approach manage and endure stress better than those who do not [3]. More dynamic approaches are needed that examine caregivers' experiences and the types of resources that help them provide good care [4]. According to Zarit and Reamy [4], we should focus on differences in caregivers' contexts, needs, and preferences. As such, this study focuses on both specific and generalized resistance resources.

This paper presents findings from a study exploring two core concepts in the salutogenic theory of health, the Specific and Generalized Resistance Resources (SRRs/GRRs), which promote positive health outcomes, and the Specific and Generalized Resistance Deficits (SRDs/GRDs), which result in negative health outcomes. The concepts explored originate from the environmental and contextual (EC) domain of caregivinghood, an evidence-based new concept used to describe a time of life characterized by caregiving of relatives at home.

\subsection{Background}

International policy documents use key concepts such as independence, participation, dignity, care, and self-fulfillment to provide health-promoting contexts for older adults [5-7], a group that includes an increasing number of older caregivers and care recipients. The World Health Organization (WHO) policy framework Active Ageing [8] was intended to inform the design of action plans that promote health and active aging. Active Ageing is the foundation for the resolution Strengthening Active and Healthy Aging at the 59th World Health Assembly [9]. Other concepts describing aging are healthy aging, successful aging, and positive aging [10]. Healthy aging may include the possibility for people to age in place- "the ability to live in one's own home and community safely, independently, and comfortably, regardless of age, income or ability level" [11]. This approach requires adequate supports be provided to older people, both caregivers and care recipients. In line with this, the WHO coined the concept of age-friendly communities, policies, and services, a concept that implies physical and social environments are designed to help older people age actively [10]. Core principles of universal design were formulated in the "Tomar Resolution" to guide professionals and all occupations working in the built environment [12]. The Ottawa Charter for health promotion formulated objectives and strategies for health promotion; creating supportive environments is one of five strategies identified in the Charter [5]. Health promotion is the process that enables individuals and communities to use their resources to increase control over their health determinants, enabling them to achieve a good quality of life [5,8]. Here health is considered a resource for everyday life. The salutogenic approach, a resource-oriented view of people and their abilities to run an active life, has been suggested as a fruitful way to advance theory and practice towards positive health development $[3,13,14]$. Research using the salutogenic approach should therefore focus on caregivers' health resources in a local context so findings could be used to develop initiatives and policies that promote their health and wellbeing $[3,10]$.

\subsection{The Aim of the Study}

This study examined the salutogenic core concepts Generalized and Specific Resistance Resources and Deficits identified by Swedish informal caregivers as originating from their environments and contexts. 


\subsection{The Theoretical Framework}

In the late 1970s, medical sociologist Aaron Antonovsky introduced salutogenesis [15], a concept that focuses on the resources for a positive health development in stressful situations such as caregiving. Salutogenesis can be applied to individuals, groups (families) [16], or communities (societies) [17] and refers to the core concepts Sense of Coherence (SOC), the Generalized And Specific Resistance Resources (GRRs/SSRs), and the Generalized And Specific Resistance Deficits (GRDs/SRDs). According to salutogenic theory, internal, external, and contextual factors determine the presence of SRRs/GRRs and SRDs/GRDs. Salutogenic theory views life as a problem-solving endeavor that requires individuals to use internal resources and immediate environmental resources to deal with everyday challenges as well as health challenges. Antonovsky labels this ability to comprehend the whole situation and a capacity to use available resources to resolve these challenges as Sense of Coherence (SOC). Over the years, salutogenesis has been established in health promotion as a complement to the pathogenic framework [18,19]. As opposed to the pathogenic framework, where health is viewed as a dichotomy between health and disease, the salutogenic theory views health as a continuum stretching from health/ease to dis-ease [15,20]. The SOC reflects a person's view of life and is a global orientation to view life as structured, manageable, and meaningful. It is a personal way of thinking, being, and acting, with an inner trust, leading people to identify, benefit, use, and re-use the resources at their disposal [21]. According to Antonovsky, SOC consists of three dimensions: the ability to understand (i.e., comprehensibility), to manage (i.e., manageability), and to make sense of (i.e., meaningfulness) challenges to health and wellbeing [20]. More recent research shows that the SOC seems to be a multidimensional construct [19]. Prerequisites for a strong SOC are found in the Specific and Generalized Resistance Resources (SRRs/GRRs). These resources derice from the material and non-material biological, cognitive, psychosocial, and socio-cultural characteristics of individuals, groups, and environments $[15,20]$. GRRs constitute what people need to draw upon their own SRRs to experience health, quality of life, and wellbeing. The key is not only what SRRs/GRRs are available but also the person's ability to use and re-use SRRs/GRRs to resolve challenges that create tension in life [21].

\subsection{Caregiving by Informal Caregivers}

Defining an informal caregiver is problematic, since caregivers primarily must define themselves as such [22]. In this study, caregivers are defined as "a person who provides unpaid care to someone with a chronic illness, disability or other long-lasting health or care need, outside a professional or formal framework" (http://www.eurocarers.org/). When caregiving became an issue in research and professional discourse in the late 1980s, caregivers' health was investigated mainly from a pathogenic perspective, and being an informal caregiver was assumed to be a major stressful event hazardous to the caregiver's health. Consequently, the focus was mainly on risk-factors for poor health and mental health. Concepts used in these early stages of caregiving research included anxiety, caregiving burden, depression, and strain [23-26]. A multitude of interventions were developed to reduce harmful effects caused by risk factors and these were assumed to enhance caregivers' wellbeing [27-30]. During the 1990s, this focus started to shift and research regarding positive aspects associated with providing care increased [31-34]. Research in this field evolved to encompass a broader focus on psychosocial aspects such as wellbeing [35], occasionally in new ways and settings [36]. Studies combining both positive and negative aspects began to appear [37-39] and the complex existential dimension of caregiving came into focus through concepts such as meaning [40-43] and quality of life [36,44,45].

\subsection{The Current State of Research on Caregiving}

Coping with informal caregiving in old age has been described in terms of content, difficulties, and satisfaction [46]. Among caregivers to older adults the most studied population has been caregivers to cognitively impaired care recipients, although other conditions have attracted increasing interest, 
such as cancer [47-49], stroke [2,45,50-54], home-based dialysis [55], heart failure [56], multiple sclerosis [57-59], dementia [60], and amyotrophic lateral sclerosis (ALS) [61]. Caregiving research has also emerged from new geographical areas, including Japan [36,62,63], Taiwan [64], China [48,55], and so-called developing countries [65-67]. Gender aspects have been granted specific attention, such as the male caregiver experience $[59,66,68-72]$ as well as issues related to relationships with spouses $[44,73,74]$ and adult children caring for aging parents [62,75].

Quantitative studies with pathogenic approaches measuring negative aspects of caregiving among caregivers providing aid to cognitively impaired care recipients still dominate research even though the use of different approaches has increased. During the 2000s, research was concerned with issues such as, gender, impact of caregiving on relationships, assessment of support needs and delivery of support, and the caring experience of caregivers in a range of groups and contexts. Due to findings from this research, much has been accomplished to support caregivers, but societies are still struggling to find better solutions. A more fruitful perspective-a salutogenic perspective-may assist with the growing public health problem for caregivers' health.

\subsection{Salutogenesis and Caregiving Research}

Antonovsky [20] developed the Orientation to Life Questionnaire (OLQ) to measure SOC quantitatively. The questionnaire has been validated and used extensively in multiple contexts [76]. In caregiving research of older adults, most studies that have used the salutogenic framework are cross-sectional, quantitative, and used the OLQ with older adults. Until 1990, only two studies had used the OLQ for older adults [77,78], although neither focused on caregivers. Wells and Kendig [79] used the SOC-13 questionnaire for exploring the views of life of caregivers and non-caregivers. They found that caring for a spouse often seriously threatens the meaningfulness of life. More recently, Coe et al. [80] examined perceived burden among 148 caregivers to chronically ill older adults recruited from 22 programs delivering different services irrespective of the care recipients' impairment or disease. Findings by Coe et al. are usually in agreement with findings from general caregiving research and caregiving research using salutogenic theory conducted during the two decades that have elapsed since their work. In line with later findings, the experience of burden seems related to caregiver characteristics (e.g., SOC) and caregivers' efforts to prevent problems more than to care recipients' functional level and care needs [45].

\subsection{Salutogenesis among Caregivers to Adult Swedes-Quantitative Designs}

SOC measured in a population of caregivers for stroke survivors during the first acute phase following the stroke were found to equal the SOC of Swedish population sample, and there were no gender or age differences in this sample [51]. Initially, Forsberg-Wärleby et al. [51] found coping ability and the appraisal of future life situation to be significantly related to psychological wellbeing but not to an objective state of impairment. The association between objective impairment and caregiver SOC did not change over time, but a higher SOC was associated with higher satisfaction with life in general, closer relationships, a better financial situation, an optimistic view of their partner's future health, and their own coping capacity [51]. A Swedish national study (https://snacsweden.wordpress.come), using the SOC questionnaire completed by caregivers found a strong SOC was related to less burden and better subjective health than a weak SOC in two slightly different populations of caregivers to older adults with mild dementia and a high degree of independence $[81,82]$. The authors surmised that caregivers with a weak SOC found the situation less comprehensible, more difficult to manage, and less meaningful than those with strong SOC, and that their lack of resources led to negative health outcomes [82]. Ekwall Kristensson and Rahm Hallberg [83] studied associations between gender, extent and content of care, satisfaction, coping, and difficulties in the caregiving situation among caregivers aged 75 and over. Although men and women had comparable SOC values, men found more satisfaction in caregiving than women. Therefore, women may be less protected against the negative aspects of caregiving than men. Those who found the most satisfaction also used more problem-focused coping 
than others [83]. Using the same population, another study found an association between strong SOC and high mental quality of life and more self-sustaining coping strategies [84]. Although the SOC questionnaire has been extensively used to assess caregivers' capability to cope, frequently resulting in recommendations to design interventions to strengthen caregivers' SOC [50,51,85], such use may be suboptimal. The SOC encompasses much more than coping capability and using the SOC scale is not the same as being guided by the salutogenic approach $[14,86]$.

\subsection{Salutogenesis among Caregivers to Adults-Qualitative or Mixed Designs}

In the early 2000s, Milberg and Strang [47,87-89] used the salutogenic framework as a theoretical foundation when investigating facilitating as well as burdensome aspects among caregivers to patients enrolled in palliative homecare. Through the use of this framework, the authors derived an understanding they assumed another approach would not have acquired, an understanding essential for the development of palliative homecare services [89]. Another Swedish research team examined the SSRs/GRR as well as the SRDs/GRDs among Swedish caregivers to older adults [90-92]. Wennerberg et al. here coined the concept caregivinghood and presented four domains of GRRs and GRDs. SOC has been used to discuss findings from other Swedish studies among caregivers [93,94], but even if the designs were qualitative, few researchers, with the exception of Milberg and Strang [47,87-89]. Studies involving caregivers to older adults using qualitative methodology and salutogenic theory outside Sweden are mainly concerned with particular populations of caregivers $[65,66]$. Most of these studies used the salutogenic framework to code and present findings.

Only two previous studies have explored caregiver GRRs. Potgieter and Heyns [65], who did not set out to detect GRRs, nevertheless identified support seeking, remaining future oriented, and religiosity as GRRs. Milberg and Strang [88] developed a theoretical framework concerning family member's experiences of palliative homecare staff based on a secondary analysis of four previous studies and presented five GRRs related to staff input (i.e., competence, support, spectrum of services, continuity, and accessibility) and two related to staff interaction (i.e., being in the centre and sharing caring).

\section{Materials and Methods}

The salutogenic theory [20] was the basis for exploring how caregivers describe resources and deficits related to caregiving stemming from their immediate context. We therefore considered a theory-driven, and qualitative study design the most appropriate. The context is essential when the intention is to unravel GRRs/SRRs and GRDs/SRDs, since they may be individualized, shared, and/or contextual $[15,20]$.

\subsection{Participants and Recruitment Process}

Participants were recruited through the managers responsible for informal caregivers in a municipality in western Sweden [95]. Included were primary caregivers to an older adult (65+) living in the municipality. Excluded were caregivers enrolled in an end-of-life program (2-5 annually) since their situation differed considerably from that of most caregivers. The total number of participating caregivers was 32 (17 wives, nine husbands, and six daughters). Background data regarding the caregivers and care recipients are presented in Table 1. 
Table 1. Characteristics of caregivers, care recipients and the context.

\begin{tabular}{|c|c|c|c|c|}
\hline Caregiver Characteristics & Wife $(n=17)$ & Husband $(n=9)$ & Daughter $(n=6)$ & Total $(n=32)$ \\
\hline Mean age (range) in years & $71(60-84)$ & $78(67-87)$ & $58(50-69)$ & $71(50-87)$ \\
\hline Professional nursing experience (mean and range in years) & 9 & 1 & 4 & 14 \\
\hline Care Recipient Characteristics & Women $(n=15)$ & Men $(n=17)$ & & Total $(n=32)$ \\
\hline Mean age (range) in years & $\begin{array}{l}\text { Wives } 77(67-86) \\
\text { Mothers } 89(76-97)\end{array}$ & $76(63-86)$ & & $77(63-97)$ \\
\hline \multicolumn{5}{|l|}{ Physical disease and/or impairment requiring assistance } \\
\hline None & 4 & 1 & & 5 \\
\hline One to two & 7 & 9 & & 6 \\
\hline Three or more & 4 & 7 & & 11 \\
\hline Extensive difficulties with communication & 4 & 3 & & 7 \\
\hline $\begin{array}{l}\text { Psychological impairment including psychiatric morbidity, } \\
\text { excessive anxiety and dementia }\end{array}$ & 11 & 11 & & 22 \\
\hline Blind, deaf or extensive limitations with sight/hearing & 2 & 5 & & 7 \\
\hline Capability to be alone & 1 & 0 & & 1 \\
\hline Never & 3 & 3 & & 6 \\
\hline Short periods of time & 6 & 1 & & 7 \\
\hline $\begin{array}{l}\text { A few hours } \\
\text { Always }\end{array}$ & 6 & 1 & & 7 \\
\hline \multicolumn{5}{|l|}{ Contextual Characteristics } \\
\hline \multicolumn{5}{|l|}{ Place of living } \\
\hline Rural area & 3 & 3 & & 6 \\
\hline Urban area & 20 & 6 & & 26 \\
\hline \multicolumn{5}{|l|}{ Nature } \\
\hline Close by $<300 \mathrm{~m}$ & 23 & 9 & & 32 \\
\hline Don't have time to go out & 2 & 0 & & 2 \\
\hline Doesn't use nature due to other reasons & 3 & 0 & & 3 \\
\hline
\end{tabular}

\subsection{Data Collection}

Data were collected through face-to-face interviews with each participant in 2006. A list of names was received from the care managers. Each caregiver was contacted by the primary investigator and interviewer (PI) via telephone, informed about the study orally, and thereafter also informed in writing about the study. Interview arrangements were made according to the interviewees' wishes: 20 caregivers were interviewed in their own homes and 12 were interviewed at the municipal hall.

\subsection{Interview}

The interview was a conversation that focused on the interviewee's contextual and environmental resistance resources using a technique called salutogenic interviewing [90,96-98]. Salutogenic interviewing is an interactive and conversational technique focused on caregivers' resources for tension management and on their health resources. The salutogenic foci shed light on questions regarding why, how, and why not when caregivers described challenges they encountered in their caregiving situation [90-92]. Demographic and contextual data, as well as questions about positive aspects in the caregiving situation were gathered. The interview questions inspired participants to reflect on their satisfaction with the caregiving situation, difficulties experienced, and strategies for managing these. The salutogenic framework guided the interview. The phases of the interview and their intended functions during background data collection are described in detail elsewhere $[6,94,95]$.

\subsection{Data Analysis}

The analysis was theory driven, qualitative, and conducted in both an inductive and deductive manner [99] guided by memos [100]. Analytical memos were hunches and ideas related to the process of unravelling SSRs/SRDs, whereas methodological memos referred to the research process per se $[90,101,102]$. Depending on individual contexts and in line with salutogenic theory, different types of tension management were used by participants to resolve the same type of challenge. Due to these context-related differences, each interview was first inductively coded using within individual case analysis [103] to extract codes referring to positive and managing aspects, the how and why, in each caregiver's description (SRRs). The question why not was used to extract codes referring to specific 
resistance deficits. Deduction was used across multiple cases [103] to identify characteristics that may function as generalized resistance resources and deficits for the caregivers. According to Ayres [103], a strategy to integrate both within individual case analysis with an across multiple case analysis is a sufficient way to produce contextually grounded and generalizable findings in qualitative research. In this paper, the caregivers' environmental and contextual (EC) domain is presented. An example of the analytical strategy of a within individualized case and an across multiple case analysis is presented in Table 2.

Table 2. An example of the analytical strategy of a within individualized case and a across multiple case analysis used in this study [103].

\begin{tabular}{cccc}
\hline Comparison & Purpose & Strategy & Product \\
\hline Within individual caregivers & $\begin{array}{c}\text { Identify variation GRRs } \\
\text { and GRDs }\end{array}$ & $\begin{array}{c}\text { Close reading of individual } \\
\text { interviews and memos }\end{array}$ & Themes (GRRs and GRDs) \\
\hline Across multiple caregivers & $\begin{array}{c}\text { Identify variation around } \\
\text { GRRs and GRDs }\end{array}$ & Data coding and display & Sub-themes (GRRs and GRDs) \\
\hline
\end{tabular}

\subsection{Ethics}

Permission to conduct the study was obtained from the municipality's political council and the highest official responsible for care of older people in this municipality. The study follows the ethical guidelines formulated by the Swedish Council for Research in the Humanities and Social Sciences (HSFR) [104]. All caregivers were first contacted by the care managers and informed about the study objectives and procedures, consistent with ethical guidelines [104]. If the caregiver decided to participate, they were mailed an information letter that included the time and location for the interview. Informed consent was obtained before the interview.

\section{Results}

The environmental/contextual domain (EC) features aspects of caregivinghood emanating from the physical environment or context in which caregiving takes place. The caregivers' "workplace" is the context-the caregiver's and care recipient's home-where caregiving work is carried out. Informal caregiving at home has certain material characteristics and is situated in an environment containing other material characteristics (e.g., geography and infrastructure). The municipality and its inhabitants also have certain characteristics (e.g., organization of welfare-/support systems, policies, values, norms, culture, and climate) that are cognitively assessed and thus considered to represent immaterial characteristics. In this study, caregiver support is considered an immaterial characteristic, since it stems from the outer context in which caregiving takes place. No definitive line was drawn between material and non-material characteristics since this was of minor importance for how caregivers seemed to perceive their SRRs/GRRs and SRDs/GRDs.

GRRs and SRRs reflect environmental and contextual characteristics. GRDs, including SRDs, encompass aspects that hamper, counteract, or obstruct the use of SRRs/GRRs and mainly reflect what is lacking in the environment and context. Both GRRs and GRDs may thus be material or immaterial and neither caregiver nor care recipient can change the location of the workplace. The environmental and contextual generalized resistance resources and deficits among informal Swedish caregivers are shown in Table 3. 
Table 3. Environmental and contextual Generalized Resistance Resources and Deficits among informal Swedish caregivers.

\begin{tabular}{ll}
\hline Generalized Resistance Resources (GRRs) & Generalized Resistance Deficits (GRDs) \\
\hline Theme & Theme \\
Being in empowering surroundings & Struggling in impeding surroundings \\
\hline GRRs & GRDs \\
Caregiving in enabling surroundings Caregiving in relative ease & Caregiving in hampering surroundings \\
Having access to appropriate support & Being presupposed to act and behave in a way expected by others \\
& Lacking access to appropriate support \\
\hline
\end{tabular}

\subsection{Generalized Resistance Resources, GRRs}

\section{Being in Empowering Surroundings}

Being in empowering surroundings unites the essence of being able to use the specific and generalized resistance resources stemming from their environment and caregiving situation to enable and facilitate as good a care as possible.

\subsection{Caregiving in Enabling Surroundings}

Caregiving in enabling surroundings was a GRR directly related to the place where care was provided, here labelled as "workplace" (not to be confused with regular workplaces with collective agreement). Experiencing that the workplace was enabling indicated a fit between the premises and what was required for using SRRs dependent on the caregiver's and care recipient's capabilities and competences. Facilitating aspects included the workplace itself being accessible from the environment and that bedrooms, bathrooms, and kitchens provided enough space to accommodate assistive devices that enabled the care recipient to move/be moved about easily. The workplace could also be enabling if it facilitated co-workability. These factors were mentioned as SRRs facilitating the caregiver's work, but they were also mentioned when caregivers explained why they were unable to manage certain things (why not indicating SRDs).

All caregivers who had moved to Senior Accommodation (SA) or Assisted Living Facility (ALF), a type of housing adapted and reserved for older adults with special needs regarding accessibility to service and the indoor and outdoor environment, did so after wavering and queuing for an apartment. Common to their experiences were the gains made through this move; the facilities' enabled these caregivers to regain access to SRRs that environmental SRDs had made unusable in their homes:

It [moving] was an ordeal ... but the older ladies living here are really nice to talk to ... we've got barbeques, play card-games ... just outside in our garden it's really social ... I really talk a lot more here than back home! ... [A]partments are disability adapted... can pop down to do my shopping, no problem! ... [T] hey have got these carts on wheels ... just bring it up in the elevator! (CG, 19)

Being in familiar surroundings is a SRR that was described as enabling the caregiver and care recipient to obtain easy access to the companionship of old friends and sources for significant memories (their roots). Most care recipients were deeply rooted where they currently lived and had lived there for a long time.

Closeness to nature was an important prerequisite for using several SRRs/GRRs. Being able to venture out into nature or the garden enhanced wellbeing for the caregiver and, when possible, the care recipient. Most caregivers spent their breathing spaces in solitude in their gardens when they needed a short break from caregiving. For other caregivers, walking outside daily was the only usable SRR that always calmed agitated care recipients. All apartments without gardens were situated close to nature and all SA/ALF complexes had accessible gardens and walkways.

Residing close to nature sometimes induced problems associated with transportation for shopping or other errands within the time a care recipient could be alone or for socializing anywhere away from 
the care recipient's home. Therefore, being close to public transportation or services that could be reached by foot or bicycle or being able to drive a car were essential SRRs.

\subsection{Caregiving in Relative Ease}

The GRR brings together SRRs related to the specific reasons for caregiving, developments over time, and comparisons with other caregivers' situations. Being in the early stages of a caregiving career, experiencing a slow decline or impairments affecting one care recipient function at the time, was described as enabling both parties to adjust in a facilitating fashion: "Well he received the diagnosis in 2000 [Alzheimer's disease, interview in 2006] . . . the progress has been very, very slow ... he's been very stable ... it's been developing successively" (CG 5). Favourable comparisons could also be made vis-à-vis other caregivers' situations ("I'm rather well off since I haven't got any heavy lifting and he's not demented ... I know what's out there!" (CG 2). Changes in care recipients' health status could be perceived as easing, regardless of whether it deteriorated ("From my point of view it has improved ... even if she has deteriorated [into dementia]", CG 29) or improved ("In the beginning he was up at least six times and so was I ... Now he can do everything ... he can't read, but he can move, walk around the garden, talk to people", CG 9). These comparisons ignore degree of burden; they show only an awareness that caregiving had become easier compared for them than other caregivers.

\subsection{Having Access to Appropriate Support}

Support was considered a GRR if it was enabling and facilitating when facing challenges. SRRs about positive experiences of accessing help and assistance are grouped together in the GRR Having access to appropriate support unites the essences of SRRs ability to encourage positive life experiences derived from having access to appropriate types of support. Such support, given when caregivers faced challenges, ensured any assistance was fitted to caregivers' individual requirements and made a positive outcome more likely.

Encounters with professionals who interacted courteously and considerately with caregivers facilitated caregivers' use of SRRs. Such interactions included how people were given advice, information, or support. Caregivers felt appreciated, proud, and confirmed in their role when they and their care recipient were fairly, respectfully, and empathetically treated by professionals providing direct support in their home:

They [home helpers] think I'm very good ... [to] take care of him the way I do. [It] facilitates their work when they have a lot to do in the mornings ... [They] don't have to care for him, only put on his clothing, everything is laid out for them ... [They] take him up and put him in his chair ... [I] receive a lot of praise [laughs]. (CG 19)

Affirmation from the municipality, for example through the yearly invitation to attend a local revue and complimentary dinner, was mainly described as generating happiness and gratitude. Most caregivers referred to this invitation positively, some ironically implying that it was crazy to think that they could spare the time, while a few were altogether negative and implied that this was all the municipality did in return. Feeling secure and content with formal support was an important SRR that enabled caregivers to do their work or take a break without too much hassle:

The support I get is good; they've told me that if I need more, I'll just call, so I know that I can if I need more help. [Interviewer: Does that sense of security help you manage?] Yes, it's comforting to have home nursing. I can talk to her [homecare nurse] if something's bothering me. (CG 18)

It was also crucial to feel secure when the care recipient and/or caregiver interacted with professionals at formal care facilities the care recipients frequented alone. If disagreements with staff occurred, this type of support could become a SRD; however, if it provided security, it was 
described as a SRR. Some types of formal support were ambiguously described, such as participating in a self-help group. The ambiguity was due to when and where it was conducted and its content. Having a safety alarm was also ambiguously described; mostly it was a SRR, but if the care recipient was not able to use it reliably, it was described as causing more trouble than being without a safety alarm. The most frustrating ambiguous type of support was the municipal transportation service, which was mostly facilitating for caregivers who were granted it in their own right and when the care recipient was granted a companion (SRR). However, the organization required to use SRDs such as transport was frequently described as a significant barrier rather than an enabler.

\subsection{Generalized Resistance Deficits, GRDs}

Struggling in Impeding Surroundings

This theme groups experiences of physical environments or contexts that hamper and obstruct the use of available SRRs/GRRs.

\subsection{Caregiving in Hampering Surroundings}

SRDs grouped together in this GRD were material or non-material features of the workplace that fitted poorly with either the care recipient's capability or the caregiver's task demands. "She's got a shower she's almost incapable to get into ... she can't help with the dishes since she has to sit on her side in the wheelchair as the kitchen is so narrow". (CG16) Similar constraints were also noted with respect to venturing outside:

It's an ordeal ... I have to order transport ... to carry her down the stairs since here's no lift ... to go through that to get a breath of air ... or to visit ... It's sort of not worth it because you have to book when you need assistance in again and sometimes she needs to go earlier, loo or something, and I have to reschedule and they can't get there in time ... you really should be able to go when you need to! (CG 16)

Caregivers' daily walks (SRR) frequently provided them with breathing spaces regardless of whether they walked alone or with their care recipients. Not being able to use this SRR for weeks, due to bad weather, for example, or lack of road maintenance (SRDs), was described as causing psychological strain, irritability, and physical deterioration negatively affecting both parties.

\subsection{Being Presupposed to Act and Behave in a Way Expected by Others}

This GRD refers to caregivers' negative perceptions of societal obligations and others' expectations. The SRDs grouped in this theme came from their immediate (e.g., family) or outer (e.g., care providers and media) context. Most statements described caregivers' reactions when they were expected to comply with invisible rules or regulations against their own best interests, such as having to accept the authority of professionals who they perceived were wrong:

She behaved strangely ... thought she'd had a small stroke ... but they didn't listen to me at the hospital ... had their minds set it was a urinary infection ... sent her home by lunchtime ... we sent her back at five and finally they listened to me. (CG 30)

When [my husband] goes to the doctor, he's told him that he's not to tell me about his conditions. When I ask [the doctor], he just refers to [husband's] integrity and doesn't tell me. REALLY! I think doctors should be obligated to tell the one who's providing care! Especially since [my husband] SAYS he doesn't remember what the doctor said. (CG 3)

Disrespect in the form of ignorance regarding caregivers' efforts or situations was exemplified by professionals who did not comply with previous agreements or caused delays. Such behaviours increased caregivers' workloads and obstructed SRR/GRR-usage: 
I should have some medication ... called down and they said, "just pop down and collect them" and down I went and there was NO medication. Then it happened again. I ordered and they said I could pick them up. NOTHING. They weren't there! [They] hadn't even ordered it! I find this utterly disrespectful. (CG 31)

Children and others were frequently described as having opinions regarding how caregivers should live their lives or did not understand that the care recipient was as impaired as the caregiver stated. Caregivers found this attitude excusable, since adult children lacked the whole story, but it hurt to be presumed to exaggerate. Subsequently, some caregivers refrained from revealing their thoughts and thereby missed opportunities to receive support. One caregiver was amazed that everyone, including his support group, had a preconceived opinion about his caregiving capability:

It doesn't make a heck of a difference where you are, you always hear the same "well we're always wondering how long you'll manage". [I'll be] damned if that's any of their business! Not one damned bit!" (CG 30)

The broader community expressed itself in a similar attitudes through the media, frequently portraying caregiving in form of negative scenarios: "Almost the first thing we heard about Alzheimer's after she got the diagnosis was ... next day. The headline was 'Alzheimer's: The death before dying'. That's not really something you'd like to hear!" (CG 10)

Some caregivers contributed to maintaining an incorrect picture of how care worked because they concealed how difficult it could actually be. They struggled to maintain the image of whom they were presumed to be as they brought grandchildren home for babysitting or prioritized children's house maintenance before their own. Some caregivers even guarded this self-image with excuses, such as having lost interest, despite it being obvious that it was not the interest that had vanished, only their ability to use the necessary SRRs.

\subsection{Lacking Access to Appropriate Support}

Reports of not receiving appropriate support when needed to deal with challenges were grouped together in the GRD Lacking access to appropriate support. Being provided with inappropriate support exacerbated lack of fit between available SRRs/GRRs and a desired outcome. This kind of support did not take the entire situation into consideration, or induced more SRDs and challenges than the ones it was supposed to diminish, and caregivers thus refrained from using it.

Professionals' performance in caregivers' homes was less often a source of frustration than the organization and its rules for accessing different types of support. The municipal transportation service was the most frustrating kind of formal support. The regulations for being granted it were described as outrageous and no one who had access to it stated that using it was enabling. It was difficult to fulfil requirements to obtain transport, especially if a grant for an accompanying person was needed. To use it required careful planning, lengthened the time for transportation, and was sometimes costly. Some care recipients had to cross municipal borders when travelling to physiotherapy or other rehabilitation; such arrangements frequently made transport so costly that they did not persist. Caregivers provided lengthy descriptions of their ordeals with this service during different parts of the interview:

[Interviewer: Are you allowed to accompany your husband?] Are you completely mad!! In that case he would have had to be so sick that he couldn't sit in a car from point A to B!!! It's completely hysterical! If he's to take this service to town I'm supposed to take a bus or a car to meet him down there for such as shopping because he can't move around in the shops by himself, can he? If I'm to do this, we may as well take the car! And these regulations, they only grant him six months and then he's got to get a doctor's certificate again. How can people who decide this be so ignorant concerning different functional 
limitations that they don't understand that a person who is 77 years old and have had several strokes will not be healed in six months! It's outrageous! (CG 4)

This caregiver also described direct negative health impacts on the care recipient of inappropriate travel arrangements:

Finally, he got rehabilitation in [another municipality]; it took him one hour to get there and then physiotherapy one hour and one hour home but ... the Taxi sort of went around to several community centres to drop people off so he got motion sickness and it took him hours to get home and when he did he was exhausted ... now I drive him. (CG 4)

The provision of formal support was mainly criticized in two ways: not being able to influence when assistance was delivered and not receiving "good quality" assistance. These aspects were mentioned by caregivers to explain why they refrained from having home helpers; they did not want different people invading their home at hours they could not choose or they wanted assistance during hours they were not granted (e.g., evenings and weekends). Another example came from caregivers who, after activating the safety alarm to call for assistance, waited a long time until staff finally showed up; subsequently, they refrained from trying again and performed the work on their own. Another quality aspect was lack of affirmation (in the caregiving role). For example, a daughter stated that her allowances seldom came when they were supposed to and no one called to ask how she was managing. Such aspects still made her feel unappreciated as a caregiver and a person, even though she had been caregiver for decades.

\section{Discussion}

This paper presents data from a study thoroughly embedded in salutogenic theory and designed to unravel the content of four central concepts within this theory: the SRRs, GRRs, SRDs, and GRDs. These concepts are helpful in conceptualizing individuals' capacity to address life's challenges and to manage the resulting stress. The ability to manage the stress associated with caregiving is apparent among Swedish informal caregivers. Both positive and negative caregiving experiences were reported. SRRs/GRRs result in positive caregiving experiences, while SRDs/GRDs induce negative ones $[15,20,105]$. To describe the content of these concepts may therefore be considered essential when conducting health promotion initiatives and programs [3].

According to the salutogenic theory, internal, external, and contextual aspects determine the presence of SRRs/GRRs and SRDs/GRDs, so the context in which a study is conducted is closely interlinked with the results. The participants in the study were informal caregivers to older adults residing in a medium-sized Swedish municipality [90], so the presented SRRs/GRRs and SRDs/GRDs are closely interlinked with this context. The study design showed that it was possible to gather qualitative data describing the GRRs/GRDs of informal caregivers. This type of data was scarce when the study was conducted and still is. Since using a salutogenic approach has been fruitful when promoting health in different contexts [106], it was used to acquire consistent knowledge regarding caregivers' GRRs/GRDs that could be used to develop different types of caregiver support missing from Swedish municipalities [107].

\section{SRRs/GRRs and SRDs/GRDs Described by Swedish Informal Caregivers}

Data enabled us to make a generalized synthesis of results [40] describing how these salutogenically approached caregivers seemed to manage their caregiving situation. They described their effectiveness as a care provider for an older adult as well as their own health related to their ability to use SRRs/GRRs and their experienced SRDs/GRDs.

The theme Being in empowering surroundings unites the essence of being able to acquire a fit between available SRRs/GRRs originating from the environment and context in which caregiving takes place and caregivers' desired outcomes when facing challenges. Struggling in impeding 
surroundings brings together the caregivers' experiences of the environmental/contextual SRDs/GRDs that counteract their ability to acquire this fit (i.e., induces a lack of fit), so their capability to use available SRRs/GRRs was lost. This loss may be temporary until other usable SRRs/GRRs are found. SRRs may be inconsistent as some SRRs are usable only during certain conditions (e.g., walking outside is possible only if the weather fits the person's capability on that day). SRRs/GRRs become permanently lost when an escalating number of individualized SRDs reaches a certain individualized level (e.g., accumulation of impairments and lack of appropriate support to bridge the gap between available SRRs and present SRDs). This level indicates the breaking-point: when caregiving in the care recipient's home ends [108].

The results indicate the importance of considering the caregiver and care recipient as individuals as well as a unit when assessing their support needs. The care recipient's home is the caregiver's "workplace"; in the case of spousal caregiving, the caregivers also work in their home. At this "workplace", the caregiver is the main provider of care, but through co-operation with the care recipient. Another consideration was when support, such as home adaptations, did not enable co-operation between the caregiver and care recipient. The caregiver's "workplace" obstructed her/his attempts to encourage the care recipient to use what remained of her/his SRRs, thereby potentially increasing the caregiver's workload. Since 2009, legislation in Sweden has obligated municipalities to support caregivers, although a follow-up audit showed that the municipalities still did not provide the good quality individualized, flexible support that caregivers needed and wanted [107].

When designing health promoting programs and support for informal caregivers it is important to take their GRRs and GRDs into consideration. They have to be more generalized to meet the needs from the caregivers. Such initiatives are described in welfare policies. These policies do not usually include criteria for entitlements that are appropriately individualized to reduce lack of fit. Regarding generalized initiatives, there seems to be a need to define what is encompassed in caregiver support [107]. Reducing the lack of fit or preserving a fit between available and usable SRRs/GRRs and a population's desired outcome seems to involve most political arenas: public transportation, outdoor accessibility and configuration, type and number of accessible apartments (housing policy), location of shops, and health care.

\section{Methodological Considerations}

The study was designed to unravel SRRs/GRRs and SRDs/GRDs in a specific context at a specific time, an approach that limits the transferability of the results, especially regarding SRRs/SRDs, which are not transferrable at all. Salutogenic interviewing is an interactive and conversational technique focused on health resources used in a particular context that seem to require that the interviewer possesses some contextual familiarity about home caregiving. Good familiarity facilitates interaction and renders an extensive diversity of data since both participants know what the other is referring to. The interviewer possessed extensive contextual familiarity derived from spending her professional life in home care settings. This experience facilitated probing and made lengthy explanations of the context unnecessary (e.g., municipal transportation service) and thus enabled the caregiver to describe the unravelling of their individualized SRRs/SRDs. The interviews highlighted variations in GRRs/GRDs and made it possible to assess the credibility of the results [101], which may be considered a methodological strength.

The data were judged to be of a sufficient scope and contextual richness to ensure trustworthiness. Specific processes were used during the analysis when structuring data and to guard against biases induced by the interviewer's preconceptions [101]. These processes have been described in detail elsewhere [90-92]. The GRRs/GRDs may be generalized enough to indicate plausible content in GRRs/GRDs originating from the environment/context in other populations [103]. 


\section{Implications for Research and Practice}

The results from this study may indicate the direction of health promotion among caregivers, suggesting a variety of approaches depending on which SRRs/GRRs and SRDs/GRDs they concern and the actors involved (e.g., professionals meeting caregivers, policy-makers, politicians at different levels, and support groups). If thorough knowledge of salutogenesis is present, we suggest that it is possible to use this study as a source of inspiration to acquire necessary data when designing health promoting activities, programs, and support even for other populations. When designing health promotion initiatives and types of support, an essential prerequisite seems to be to define what is included in caregiver support and specify what it is intended to achieve for both the caregiver and care recipient. The results from this study and recent research indicate that this support has to be conducted on two levels—individualized SRRs/SRDs and generalized GRRs/GRDs.

\section{Conclusions}

The salutogenic approach and the methodology used to unravel caregivers' Resistance Resources and Deficits in caregivinghood succeeded in improving understanding of the mechanisms involved in the development of stress management among caregivers. The results may empirically as well as theoretically strengthen health promotion research and practice in a way that develops appropriate health promoting initiatives and supports caregivers and care recipients. This support has to be both individualized and generalized.

Acknowledgments: We would like to express our sincere gratitude to the caregivers who shared their very personal experiences with us. Without your trust, this study would not have been possible.

Author Contributions: Mia M.T. Wennerberg contributed during all parts of the study, collected all data and run the analysis. Monica Eriksson had the main responsibility for drafting the manuscript and contributed to the theoretical interpretations of findings as one of the supervisors. Ella Danielson contributed to study design and planning, during analysis, with supervision and to revisions of the manuscript. Solveig M. Lundgren contributed during analysis, with supervision and to revisions of the manuscript. All authors have together critically revised the manuscript.

Conflicts of Interest: The authors declare no conflicts of interest.

\section{References}

1. European Commission. Long-Term Care for the Elderly. Provisions and Providers in 33 European Countries; European Commission: Luxembourg, 2012.

2. Mackenzie, A.; Greenwood, N. Positive experiences of caregiving in stroke: A systematic review. Disabil. Rehabil. 2012, 34, 1413-1422. [CrossRef] [PubMed]

3. Lindström, B.; Eriksson, M. The salutogenic approach to the making of HiAP/Healthy Public Policy: Illustrated by a case study. Glob. Health Promot. 2009, 16, 17-28. [CrossRef] [PubMed]

4. Zarit, S.H.; Reamy, A.M. Future directions in family and professionala caregiving for elderly. Gerontology 2013, 59, 152-158. [CrossRef] [PubMed]

5. World Health Organization (WHO). Ottawa Charter for Health Promotion: An International Conference on Health Promotion, the Move Towards a New Public Health, November 17-21 1986; World Health Organization: Geneva, Switzerland, 1986.

6. United Nations. Implementation of the International Plan of Action on Ageing and related activities. In ANNEX The United Nations Principles for Older Persons. To Add Life to the Years That Have Been Added to Life; A/res/46/91, 74th Plenary Meeting; United Nations: New York, NY, USA, 1991.

7. European Commission. European Charter of Rights and Responsibilities of Older People in Need of Long-Term Care and Assistance, EUSTaCEA Project, under Daphne III Programme; Accompanying Guide; European Commission: Luxembourg, 2010.

8. World Health Organization (WHO). Active Ageing: A Policy Framework; WHO: Geneva, Switzerland, 2002.

9. World Health Organization (WHO). Resolution Strengthening Active and Healthy Aging; WHO: Geneva, Switzerland, 2005. 
10. Koelen, M.; Eriksson, M.; Cattan, M. Older People, Sense of Coherence and Community. In The Handbook of Salutogenesis; Mittelmark, M.B., Sagy, S., Eriksson, M., Bauer, G.F., Pelikan, J.M., Lindström, B., Espnes, G.A., Eds.; Springer: New York, NY, USA, 2016; pp. 137-149.

11. Centers for Disease Control and Prevention. Healthy Places Terminology. Retrieved 27 February 2017. Available online: https:/ / www.cdc.gov/healthyplaces/terminology.htm (accesed on 27 February 2017).

12. Council of Europe. Resolution ResAP (2001) 1 on the Introduction of the Principles of Universal Design into Curricula of All Occupations Working on the Built Environment; Council of Europe: Strasbourg, France, 2001.

13. Eriksson, M.; Lindström, B. A salutogenic interpretation of the Ottawa Charter. Health Promot. Int. 2008, 23, 190-199. [CrossRef] [PubMed]

14. Antonovsky, A. The salutogenic model as a theory to guide health promotion. Health Promot. Int. 1996, 11, 11-18. [CrossRef]

15. Antonovsky, A. Health, Stress and Coping; Jossey-Bass: San Francisco, CA, USA, 1979.

16. Antonovsky, A.; Sourani, T. Family sense of coherence and family adaptation. J. Marriage Fam. 1988, 50, 79-92. [CrossRef]

17. Antonovsky, A. Complexity, conflict, chaos, coherence, coercion and civility. Soc. Sci. Med. 1993, 37, 969-981. [CrossRef]

18. Janssen, B.M.; Van Regenmortel, T.; Abma, T.A. Balancing Risk Prevention and Health Promotion: Towards a Harmonizing Approach in Care for Older People in the Community. Health Care Anal. 2014, 22, 82-102. [CrossRef] [PubMed]

19. Mittelmark, M.; Sagy, S.; Eriksson, M.; Bauer, G.F.; Pelikan, J.M.; Lindström, B.; Espnes, G.A. (Eds.) The Handbook of Salutogenesis; Springer: New York, NY, USA, 2016.

20. Antonovsky, A. Unraveling the Mystery of Health. How People Manage Stress and Stay Well; Jossey-Bass: San Francisco, CA, USA, 1987.

21. Eriksson, M.; Lindström, B. Antonovsky's Sense of Coherence Scale and the relation with health: A systematic review. J. Epidemiol. Commun. Health 2006, 60, 376-381. [CrossRef] [PubMed]

22. O'Connor, D.L. Self-identifying as a caregiver: Exploring the positioning process. J. Aging Stud. 2007, 21, 165-174. [CrossRef]

23. Goodman, C. Research on the informal carer: A selected literature review. J. Adv. Nurs. 1986, 11, 705-712. [CrossRef] [PubMed]

24. Kinney, I.M.; Stephens, M.A.P. Hassels and uplifts of giving care to a family member with dementia. Psychol. Aging 1989, 4, 402-408. [CrossRef] [PubMed]

25. Pearlin, L.I.; Mullan, J.T.; Semple, S.J.; Skaff, M.M. Caregiving and the stress process: An overview of concepts and their measures. Gerontologist 1990, 30, 583-594. [CrossRef]

26. Stephens, M.A.P.; Kinney, J.M.; Norris, V.K.; Ritchie, S.W.; Grotz, R.C. Stressful situations in caregiving: Relations between caregiver coping and well-being. Pscyhol. Aging 1988, 3, 208-209. [CrossRef]

27. Acton, G.J.; Kang, J. Interventions to reduce the burden of caregiving for an adult with dementia: A meta-analysis. Res. Nurs. Health 2001, 24, 349-360. [CrossRef] [PubMed]

28. Brodaty, H.; Green, A.; Koschera, A. Meta-analysis of psychosocial interventions for caregivers of people with dementia. J. Am. Geriatr. Soc. 2003, 51, 657-664. [CrossRef] [PubMed]

29. Cooke, D.D.; McNally, L.; Mulligan, T.; Harrison, J.G.; Newman, S.P. Psychosocial interventions for caregivers of people with dementia: A systematic review. Aging Ment. Health 2001, 5, 120-135. [CrossRef] [PubMed]

30. Deeken, J.F.; Taylor, K.L.; Mangan, P.; Yabroff, K.R.; Ingham, J.M. Care of the caregivers: A review of self-report instruments developed to measure the burden, needs, and quality of life of informal caregivers. J. Pain Symptom Manag. 2003, 26, 922-953. [CrossRef]

31. Cohen, C.A.; Colantonio, A.; Vernich, L. Positive aspects of caregiving: Rounding out the caregiver experience. Int. J. Geriatr. Psychiatry 2002, 17, 184-188. [CrossRef] [PubMed]

32. Hunt, C.K. Concepts in caregiver research. J. Nurs. Scholarsh. 2003, 35, 27-32. [CrossRef] [PubMed]

33. Kramer, B.J. Gain in the caregiving experience: Where are we? What next? Gerontologist 1997, 37, $218-232$. [CrossRef]

34. Louderback, P. What's happening. Elder Care: A positive approacah to caregiving. J. Am. Acad. Nurse Pract. 2000, 12, 97-99. [CrossRef] [PubMed]

35. Lawton, M.P.; Moss, M.; Kleban, M.H.; Glicksman, A.; Rovine, M. A two-factor model of caregiving appraisal and psychological well-being. J. Gerontol. 1991, 46, 181-189. [CrossRef] 
36. Yamamoto-Mitani, N.; Ishigaki, K.; Kuniyoshi, M.; Kawahara-Maekawa, M.; Hayashi, K.; Hasegawa, K.; Sugishita, C. Subjective quality of life and positive appraisal of care among Japanese caregivers of older adults. Qual. Life Res. 2004, 13, 207-221. [CrossRef] [PubMed]

37. Kinney, J.; Stephens, M.; Franks, M.; Norris, V. Stresses and satisfactions of family caregivers to older stroke patients. J. Appl. Gerontol. 1995, 14, 3-21. [CrossRef]

38. Nijboer, C.; Tempelaar, B.; Tiemestra, M.; Sanderman, R.; Van den Bos, C. Measuring both negative and positive reactions to giving care to cancer patients: Psychometric qualities of the caregiver reaction assessment. Soc. Sci. Med. 1999, 48, 1259-1269. [CrossRef]

39. Rapp, S.R.; Chao, D. Appraisals of strain and gain: Effects on psychological wellbeing of caregivers of dementia patients. Aging Ment. Health 2000, 4, 142-147. [CrossRef]

40. Ayres, L. Narratives of family caregiving: The process of making meaning. Res. Nurs. Health 2000, 23, 424-434. [CrossRef]

41. Ayres, L. Narratives of family caregiving: Four story types. Res. Nurs. Health 2000, 23, 359-371. [CrossRef]

42. Farran, C.; Keane-Hagerty, E.; Salloway, S.; Kupferer, S.; Wilken, C. Finding meaning: An alternative paradigm for Alheimer's disease family caregivers. Gerontologist 1991, 31, 483-489. [CrossRef]

43. Farran, C.; Miller, B.H.; Kaufman, J.E.; Donner, E.; Fogg, L. Finding meaning through caregiving: Development of an instrument for family caregivers to persons with Alzheimer's disease. J. Clin. Psychol. 1999, 55, 1107-1125. [CrossRef]

44. Kramer, B.J. Expanding the conceptualization of caregiver coping: The importance of relationship-focused coping strategies. Gerontologist 1993, 35, 340-348. [CrossRef]

45. Van Puymbroeck, M.; Rittman, M.R. Quality-of-life predictors for caregivers at 1 and 6 months poststroke: Results of path analysis. J. Rehabil. Res. Dev. 2005, 42, 747-760. [CrossRef] [PubMed]

46. Ekwall, A.K. Informal Caregiving at Old Age. Content, Coping, Difficulties and Satisfaction. Ph.D. Thesis, Lund University, Lund, Sweden, 2004.

47. Milberg, A.; Strang, P. Meaningfulness in palliative home care: An interview study of dying cancer patients' next of kin. Palliat. Support. Care 2003, 1, 171-180. [CrossRef] [PubMed]

48. Mok, E.; Chan, F.; Chan, V.; Yeung, E. Perception of empowerment by family caregivers of patients with a terminal illness in Hong Kong. Int. J. Palliat. Nurs. 2002, 8, 137-145. [CrossRef] [PubMed]

49. Waldrop, D.P.; Rinfrette, E.S. Can short hospice enrolment be long enough? Comparing the perspectives of hospice professionals and family caregivers. Palliat. Support. Care 2009, 7, 37-47. [CrossRef] [PubMed]

50. Chumbler, N.R.; Rittman, M.R.; Wu, S.S. Associations in sense of coherence and depression in caregivers of stroke survivors across 2 years. J. Behav. Health Serv. Res. 2008, 35, 226-234. [CrossRef] [PubMed]

51. Forsberg-Wärleby, G.; Möller, A.; Blomstrand, C. Spouses of first-ever stroke victims: Sense of coherence in the first phase after stroke. J. Rehabil. Med. 2002, 34, 128-133. [CrossRef] [PubMed]

52. Nilsson, I.; Axelsson, K.; Gustafson, Y.; Lundman, B.; Norberg, A. Well-being, sense of coherence, and burnout in stroke victims and spouses during the first few months after stroke. Scand. J. Caring Sci. 2001, 15, 203-214. [CrossRef] [PubMed]

53. O'Connel, B.; Baker, L. Managing as carers of stroke survivors: Strategies from the field. Int. J. Nurs. Pract. 2004, 11, 121-126. [CrossRef] [PubMed]

54. Gosman-Hedström, G.; Dahlin-Ivanoff, S. "Mastering an unpredictable everyday life after stroke" —Older women's experiences of caring and living with their partners. Scand. J. Caring Sci. 2012, 26, 587-597. [CrossRef] [PubMed]

55. Luk, W.S.-C. The home care experience as perceived by caregivers of Chinese dialysis patients. Int. J. Nurs. Stud. 2002, 39, 269-277. [CrossRef]

56. Saunders, M.M. Perspectives from family caregivers receiving home nursing support: Findings from a qualitative study of home care patients with heart failure. Home Healthc. Nurse 2012, 30, 82-90. [PubMed]

57. Cheung, J.; Hocking, P. Caring as worrying: The experience of spousal carers. J. Adv. Nurs. 2004, 47, 475-482. [CrossRef] [PubMed]

58. Topcu, G.; Buchanan, H.; Aubeeluck, A.; Garip, G. Caregiving in multiple sclerosis and quality of life: A meta-synthesis of qualitative research. Psychol. Health 2016, 31, 693-710. [CrossRef] [PubMed] 
59. Rollero, C. The experience of men caring for a partner with Multiple Sclerosis. J. Nurs. Scholarsh. 2016. [CrossRef] [PubMed]

60. Lethin, C.; Renom-Guiteras, A.; Zwakhalen, S.; Soto-Martin, M.; Saks, K.; Zabalegui, A.; Challis, D.J.; Nilsson, C.; Karlsson, S. Psychological well-being over time among informal caregivers caring for persons with dementia living at home. Aging Ment. Health 2016. [CrossRef] [PubMed]

61. Galvin, M.; Corr, B.; Madden, C.; Mays, I.; McQuillan, R.; Timonen, V.; Staines, A.; Hardiman, O. Caregiving in ALS-A mixed methods approach to the study of burden. BMC Palliat. Care 2016, 15, 81-92. [CrossRef] [PubMed]

62. Harris, P.B.; Long, S.O. Husbands and sons in the United States and Japan: Cultural expectations and caregiving experiences. J. Aging Stud. 1999, 13, 241-267. [CrossRef]

63. Yamamoto-Mitani, N.; Wallhagen, M.I. Pursuit of psychological well-being (ikigai) and the evolution of self-understanding in the context of caregiving in Japan. Cult. Med. Psychiatry 2002, 26, 399-417. [CrossRef] [PubMed]

64. Chen, M.-Y. The effect of health promotion counselling to family caregivers. Public Health Nurs. 1999, 16, 125-132. [CrossRef] [PubMed]

65. Potgieter, J.C.; Heyns, P.M. Caring for a spouse with Alzheimer's disease: Stressors and strengths. S. Afr. J. Psychol. 2006, 36, 547-563. [CrossRef]

66. Pretorius, C.; Walker, S.; Heyns, M. Sense of coherence amongst male caregivers in dementia. Dementia 2009, 8, 79-94. [CrossRef]

67. Prince, M.; Graham, N.; Brodaty, H.; Rimmer, E.; Varghese, M.; Chiu, H.; Acosta, D.; Scazufca, M. Alzheimer Disease International's 10/66 Dementia Research Group-One model for action research in developing countries. Int. J. Geriatr. Psychiatry 2004, 19, 178-181. [CrossRef] [PubMed]

68. Kirsi, T.; Hervonen, A.; Jylhä, M. A man's gotta do what a man's gotta do: Husbands as caregivers to their demented wives: A discourse analysis approach. J. Aging Stud. 2000, 2, 153-169. [CrossRef]

69. Morgan, T.; William, L.A.; Trussardi, G.; Gott, M. Gender and family caregiving at the end-of-life in the context of old age: A systematic review. Palliat. Med. 2016, 30, 616-624. [CrossRef] [PubMed]

70. Kramer, B.J. Marital history and the prior relationship as predictors of positive and negative outcomes among wife caregivers. Fam. Relat. 1993, 42, 367-375. [CrossRef]

71. Riberio, O.; Constanca, P. Older male carers and the positive aspects of care. Ageing Soc. 2008, 28, 165-183. [CrossRef]

72. Russel, R. In sickness and in health. A qualitative study of elderly men who care for wives with dementia. J. Aging Stud. 2001, 15, 351-367.

73. Calasanti, T.; Bowen, M.E. Spousal caregiving and crossing gender boundaries: Maintaining gendered identities. J. Aging Stud. 2006, 20, 253-263. [CrossRef]

74. Lewis, R.D. The impact of the marital relationship on the experience of caring for an elderly spouse with dementia. Ageing Soc. 1998, 18, 209-231. [CrossRef]

75. Romoren, T.I. The carer career of son and daughter primary carers of their very old parents in Norway. Ageing Soc. 2003, 23, 471-485. [CrossRef]

76. Eriksson, M. Unravelling the Mystery of Salutogenesis: The Evidence Base of the Salutogenic Research as Measured by Antonovsky's Sense of Coherence Scale. Ph.D. Thesis, Åbo Akademi University Vasa, Turku, Finland, 2007.

77. Coe, R.M.; Romeis, J.C.; Tang, B.; Wolinsky, F.D. Correlates of a measure of coping in older veterans: A preliminary report. J. Commun. Health 1990, 15, 287-296. [CrossRef]

78. Sagy, S.; Antonovsky, A. Coping with retirement: Does the sense of coherence matter less in the kibbutz? Int. J. Health Sci. 1990, 1, 233-242.

79. Wells, Y.D.; Kendig, H.L. Health and wellbeing of spouse caregivers and the widowed. Gerontologist 1997, 37, 666-674. [CrossRef] [PubMed]

80. Coe, R.M.; Miller, D.K.; Flaherty, J. Sense of coherence and perception of caregiving burden. Behav. Health Aging 1992, 2, 93-99.

81. Andrén, S.; Elmståhl, S. Family caregivers' subjective experiences of satisfaction in dementia care: Aspects of burden, subjective health and sense of coherence. Scand. J. Caring Sci. 2005, 19, 157-168. [CrossRef] [PubMed] 
82. Andrén, S.; Elmståhl, S. The relationship between caregiver burden, caregivers' perceived health and their sense of coherence in caring for elders with dementia. J. Clin. Nurs. 2008, 17, 790-799. [CrossRef] [PubMed]

83. Kristensson, A.E.; Rahm Hallberg, I. The association between caregiving satisfaction, difficulties and coping among older family caregivers. J. Clin. Nurs. 2007, 16, 832-844.

84. Kristensson, A.E.; Sivberg, B.; Rahm Hallberg, I. Older caregivers' coping strategies and sense of coherence in relation to quality of life. J. Adv. Nurs. 2007, 57, 584-596.

85. Zhang, J.; Vitaliano, P.P.; Lutgendorf, S.K.; Scanlan, J.M.; Savage, M.V. Sense of coherence buffers relationships of chronic stress with fasting glucose levels. J. Behav. Med. 2001, 24, 33-55. [CrossRef] [PubMed]

86. Kickbusch, I. Tribute to Aaron Antonovsky-“What creates health”. Health Promot. Int. 1996, 11, 5-6. [CrossRef]

87. Milberg, A.; Strang, P. Exploring comprehensibility and manageability in palliative home care: An interview study of dying cancer patients' informal carers. Psycho-Oncology 2004, 13, 605-618. [CrossRef] [PubMed]

88. Milberg, A.; Strang, P. What to do when 'there is nothing more to do'? A study within a salutogenic framework of family members' experience of palliative home care staff. Psycho-Oncology 2007, 16, 741-751. [CrossRef] [PubMed]

89. Milberg, A. Family Members' Experience of Palliative Home Care. Ph.D. Thesis, Linköping University, Linköping, Sweden, 2003.

90. Wennerberg, M.M.T.; Lundgren, S.M.; Danielson, E. Using the salutogenic approach to unravel informal caregivers' resources to health: Theory and methodology. Aging Ment. Health 2012, 16, 391-402. [CrossRef] [PubMed]

91. Wennerberg, M.M.T.; Eriksson, M.; Danielson, E.; Lundgren, S.M. Unravelling Swedish informal caregivers' Generalised Resistance Resources. Scand. J. Caring Sci. 2016, 30, 602-613. [CrossRef] [PubMed]

92. Wennerberg, M.M.T.; Eriksson, M.; Lundberg, S.M.; Danielson, E. Unravelling Swedish informal caregivers' Generalized Resistance Deficits. Scand. J. Caring Sci. 2017. [CrossRef] [PubMed]

93. Andershed, B.; Ternestedt, B.-M. Involvement of relatives in the care of the dying in different care cultures: Involvement in the dark or in the light? Cancer Nurs. 1998, 21, 106-116. [CrossRef] [PubMed]

94. Stoltz, P.; Willman, A.; Udén, G. The meaning of support as narrated by family carers for a senior relative at home. Health Res. 2006, 16, 594-610. [CrossRef] [PubMed]

95. Krevers, B.; Magnusson, H.; Johansson, L.; Öberg, B. (Eds.) The National Survey Report for Sweden. In EUROFAMCARE Consortium Services for Supporting Family Carers of Older Dependent People in Europe: Characteristics, Coverage and Usage; European Union: Brussels, Belgium, 2006.

96. Benzein, E.G.; Hagberg, M.; Saveman, B.-I. "Being appropriately unusal": A challenge for nurses in health-promoting conversations with families. Nurs. Inq. 2008, 15, 106-115. [CrossRef] [PubMed]

97. Hollnagel, H.; Malterud, K. Shifting attention from objective risk factors to patients' self-assessed health resources: A clinical model for general practice. Fam. Pract. 1995, 12, 423-429. [CrossRef] [PubMed]

98. Hollnagel, H.; Malterud, K.; Witt, K. Men's self-assessed personal health resources: Approaching patients' strong points in general practice. Fam. Pract. 2000, 17, 529-534. [CrossRef] [PubMed]

99. Elo, S.; Kyngäs, H. The qualitative content analysis process. J. Adv. Nurs. 2007, 62, 107-115. [CrossRef] [PubMed]

100. Birks, M.; Chapman, Y.; Francis, K. Memoing in qualitative research. Probing data and processes. J. Res. Nurs. 2008, 13, 68-75. [CrossRef]

101. Sandelowski, M.; Barosso, J. Finding the findings in qualitative studies. J. Nurs. Scholarsh. 2002, 34, $213-219$. [CrossRef] [PubMed]

102. Malterud, K. Qualitative research: Standards, challenges, and guidelines. Lancet 2001, 358, $483-488$. [CrossRef]

103. Ayres, L.; Kavanaugh, K.; Knafl, K. Within-case and across-case approaches to qualitative data analysis. Qual. Health Res. 2003, 13, 871-882. [CrossRef] [PubMed]

104. Swedish Council for Research in the Humanities and Social Sciences. Ethical Guidelines for Research in the Humanities and Social Sciences; Codex: Stockholm, Sweden, 2002.

105. Sagy, S.; Antonovsky, H. The development of the sense of coherence: A retrospective study of early life experiences in the family. J. Aging Hum. Dev. 2000, 51, 155-166. [CrossRef] [PubMed] 
106. Lezwijn, J.; Vaandrager, L.; Naaldenberg, J.; Wagemakers, A.; Koelen, M.; van Woerkum, C. Healthy ageing in a salutogenic way: Building the HP 2.0 framework. Health Soc. Care Commun. 2011, 19, 43-51. [CrossRef] [PubMed]

107. Riksrevisionen. Stödet till Anhöriga Omsorgsgivare (RiR 2014:9); Summary; Support for Carers; Swedish National Audit Office: Stockholm, Sweden, 2014.

108. Annerstedt, L.; Elmståhl, S.; Invad, B.; Samuelsson, S.-M. Family caregiving in dementia. An analysis of the caregiver's burden and the "breaking-point" when home care becomes inadequate. Scand. J. Public Health 2000, 28, 23-31. [CrossRef] [PubMed] article distributed under the terms and conditions of the Creative Commons Attribution (CC BY) license (http://creativecommons.org/licenses/by/4.0/). 